\title{
Avaliação do Potencial de Reuso Industrial de Água na Região Metropolitana do Rio de Janeiro
}

\author{
André Alcantara de Farial; Marcelo Obraczkal; Luís Carlos Soares da Silva Junior ${ }^{2}$; Bruno \\ Muricy'; Kelly Oliveiral; Ana Cecilia Monteirol \\ 凹_afaria.alcantara@gmail.com
}

1. Universidade do Estado do Rio de Janeiro.

2. Universidade Federal do Rio de Janeiro.

Histórico do Artigo: 0 autor detém os direitos autorais deste artigo.

Recebido em: 29 de outubro de $2020 \quad$ Aceito em: 29 de março de $2021 \quad$ Publicado em: 31 de agosto de 2021

Resumo: A poluição das principais fontes de água e a recorrente condição de escassez hídrica agravada pelos efeitos das mudanças climáticas, como a que ocorreu em 2014 na Região Metropolitana do Rio de Janeiro (RMRJ), afetam a disponibilidade hídrica e fomentam a busca por fontes alternativas para atendimento de demandas básicas da sociedade. Este trabalho teve como objetivo avaliar, em termos de quantidade, o potencial de oferta e demanda da água de reuso para fins não potáveis a partir dos efluentes tratados de Estações de Tratamento de Esgotos (ETEs) na RMRJ. Foram identificadas quatro ETE’s cujas características como localização e capacidade instalada de tratamento as favorecem como potenciais fornecedores de águas de reuso não potável. Como potenciais consumidores foram consideradas as indústrias de transformação no raio de $10 \mathrm{~km}$ a partir de cada ETE. 0 trabalho apresentou um inventário georreferenciado desses potenciais fornecedores e consumidores, que se configurou como ferramenta para a identificação de situações mais viáveis objetivando a implementação do reuso de efluentes para uso industrial não potável na RMRJ. Enquanto a capacidade instalada de sistemas de tratamento secundário e de produção de água de reuso disponíveis nas 4 ETE’s elencadas pela pesquisa é de $569.030 \mathrm{~m}^{3} /$ dia, o total das demandas hídricas industriais das 728 empresas consideradas pelo estudo e que podem ser atendidas por essa fonte alternativa de água é de $135.777 \mathrm{~m}^{3} /$ dia. Essa disponibilidade demonstrou o grande potencial para emprego de águas regeneradas para fins industriais não potáveis na região estudada.

Palavras-chave: Reuso de água, Abastecimento industrial, Água, Água de reuso não potável.

\section{Assessment 0f The Potential of Wastewater Reuse For Industries In The Metropolitan Region Of Rio De Janeiro}

\begin{abstract}
The pollution of the main water sources and the water scarcity, aggravated by climate change, such as that which occurred in 2014 in the Metropolitan Region of Rio de Janeiro (RMRJ), considerably affected water availability and has been encouraging the search for sources alternatives to meet basic water demands of society. This work aims to assess, in terms of quantity, the potential of treated effluent from Wastewater Treatment Plants (WTP) in RMRJ to supply industrial demands as reclaimed water for non-potable purposes. To assess the potential for reuse, characteristics which favor WTPs as reuse water generators such as location and installed treatment capacity were identified in the study area. As the main consumers, the industrial transformation typology was adopted for this research. The present study developed an inventory of these potential generators and consumers at RMRJ, which can be used as management tool in order to identify clusters for the implementation of reclaimed water for non-potable industrial use, especially around the WTPs. Considering the installed treatment capacity and the efficiency of the listed WTPs it was also possible to verify the existence of great potential for reclaimed water, considering as well the WTP proximity to industries whose industrial water demands can be supplied by this alternative source of water.
\end{abstract}

Keywords: Water reuse, Reclaimed water, Water, Water supply for industries. 


\section{Evaluación Del Potencial De Reutilización Industrial De Efluentes Em La Región Metropolitana De Rio De Janeiro}

Resumen: La contaminación de las principales fuentes de agua y la condición recurrente de escasez de agua agravada por los efectos del cambio climático, como el ocurrido en 2014 en la Región Metropolitana de Río de Janeiro (RMRJ), afectan la disponibilidad de agua y fomentan la búsqueda de fuentes alternativas para satisfacer las demandas básicas de agua de la sociedad. Este trabajo tuvo como objetivo evaluar, en términos de cantidad, el potencial de oferta y demanda de agua de reutilización para fines no potables de los efluentes tratados de las Plantas de Tratamiento de Aguas Residuales (ETEs) en RMRJ. Se han identificado cuatro ETEs cuyas características como ubicación y capacidad de tratamiento instalada las favorecen como potenciales provedores de agua de reutilización no potable. Paralelamente, se relevaron las industrias de transformación en un radio de $10 \mathrm{~km}$ de cada ETE. El trabajo generado presentó un inventario georreferenciado de estos potenciales proveedores y consumidores, el cual se configuró como una herramienta para la identificación de situaciones más viables con el objetivo de implementar la reutilización de efluentes para uso industrial no potable en RMRJ. Si bien la capacidad instalada de los sistemas de producción de agua de tratamiento secundario y reutilización disponibles en las 4 ETEs enumeradas por la encuesta es de $569.030 \mathrm{~m} 3 /$ día, las demandas totales de agua industrial de las 728 empresas consideradas por el estudio y que pueden ser satisfechas por esta fuente alternativa de el agua es de 135.777 m3/día. Esta disponibilidad demostró el gran potencial para el uso de agua regenerada para fines industriales no potables en la región estudiada.

Palabras clave: Reutilización de agua, Abastecimiento industrial, Agua, Agua de reutilización no potable.

\section{INTRODUÇÃo}

A utilização da água é um fator preponderante no processo de formação das cidades, bem como no desenvolvimento socioeconômico da população em geral. À medida que os centros urbanos crescem, a demanda hídrica aumenta (HOEKSTRA et al., 2016; Organização das Nações Unidas, 2019). Segundo o Instituto Trata Brasil (ITB, 2020), a demanda de água potável no Brasil pode aumentar quase $80 \%$ até 2040 diante de mudanças econômicas, demográficas e climáticas.

A disponibilidade (e a segurança) hídrica de regiões estratégicas do país que possuem forte dependência de águas que se situam fora dos seus limites territoriais vem sendo consideravelmente afetadas (MARENG0 et al., 2015; F0RMIGA-JOHNSSON et al., 2015). Agravada pelos efeitos das mudanças climáticas e pela poluição das principais fontes de água, situações de escassez hídrica como a que ocorreu em 2014 na Região Metropolitana do Rio de Janeiro (CAMPOS, 2018) e em São Paulo (EMPINOTTI et al., 2019) têm se tornado mais críticas e frequentes.

Diante deste cenário, se tornam imprescindíveis medidas e campanhas para racionalização e uso consciente da água, além da utilização de fontes alternativas não convencionais tais como a água de chuva e o reuso de efluentes para usos menos nobres (0BRACZKA et al., 2019). 
0 reuso de água a partir de efluentes sanitários já é uma prática corrente em vários países, principalmente naqueles onde se convive com situações de maior estresse hídrico, surgindo como uma oportunidade no seu enfrentamento e alternativa de fonte e abastecimento de água (ANGELAKIS e GIKAS, 2014; STEFLOVÁ, 2018). 0 emprego de efluentes tratados provenientes das estações (ETEs) administradas por concessionárias ou outras indústrias se configura como aplicação da prática do reuso de efluentes em indústrias (HESPANHOL, 2015) sendo que diversos autores identificam as tipologias urbana e industrial como as que apresentam maior viabilidade técnica e econômica (SILVA Jr e OBRACZKA, 2020)

Na Região Metropolitana de São Paulo (RMSP), a SABESP já atende várias demandas industriais a partir do fornecimento de águas de reuso provenientes das ETE’s de Jesus Neto (18 $\mathrm{L} / \mathrm{s})$, Parque Mundo Novo $(24 \mathrm{~L} / \mathrm{s})$ e a do ABC $(650 \mathrm{~L} / \mathrm{s})$ esta última associada ao empreendimento AQUAPOLO, o “case” de reuso de efluentes mais emblemático no país e em toda a América Latina (NOBRE, 2013; MACHAD0, 2019; MIERZWA, 2020).

Além da vazão e qualidade da água industrial demandada pelos consumidores, a proximidade geográfica entre esses e os potenciais fornecedores são destacados como os fatores mais importantes para implementação do reuso de efluentes (SILVA et al., 2019; CAMPOS, 2018). Esses autores sustentam ainda que o reuso de efluentes tratados é mais viável e economicamente atraente para o setor industrial, tendo em vista tanto seus elevados consumos como as tarifas de água potável praticadas pelas concessionárias para essas empresas.

Na RMRJ, a capacidade instalada dos sistemas de produção de águas de reuso (SPAR) se distribui nas ETE’s Alegria (1.920 m²/dia), Penha (768 m3/dia) e Deodoro (720 m³/dia) (OBRACZKA et al., 2019). Esses sistemas de polimento são compostos por uma etapa inicial de filtração "in line" do efluente do tratamento secundário, através de membrana ou tela, seguida de desinfecção pela adição de hipoclorito.

As águas regeneradas são destinadas basicamente ao atendimento de algumas demandas internas das próprias concessionárias (lavagem de veículos e equipamentos, desobstrução de redes) e a ETE Penha também fornece água de reuso para lavagem de vias e feiras pela COMLURB (NET0 e OLIVEIRA, 2008; ZAHNER FILHO, 2014 e SILVA Jr e OBRACZKA, 2020). Porém, com exceção dessas iniciativas isoladas, o reuso de efluentes de ETE’s na RMRJ é incipiente (FARIA, 2020). Segundo pesquisa de OBRACZKA et al. (2019), a vazão de reuso não chega a 0,15\% da vazão de tratamento efetiva total das principais ETE’s na RMRJ, vazão essa da ordem de $359.800 \mathrm{~m}^{3} /$ dia, enquanto a vazão outorgada de captação de água somente para uso industrial no município do Rio de Janeiro é de cerca de $79.110 \mathrm{~m}^{3}$ /dia (FIRJAN, 2019). 
0 objetivo do presente trabalho foi desenvolver um inventário de água de reuso, através de um mapeamento de alguns dos seus principais fornecedores em potencial na RMRJ, bem como de possíveis consumidores que apresentem uma maior viabilidade para serem abastecidos por essas águas regeneradas para fins industriais e não potáveis.

\section{METOD0LOGIA}

\section{ETAPA 1: Identificação dos potenciais fornecedores de água de reuso}

Para definição da área de estudo, foi considerada a localização das principais ETE’s da RMRJ que já possuem ou projetam implementar um sistema de produção de água de reuso (SPAR) em suas unidades. Para este trabalho, foram consideradas as ETE’s de maior porte na RMRJ operadas pela Companhia Estadual de Águas e Esgotos (CEDAE) (BIELSCHOWSKY, 2014), baseando-se também nas prioridades definidas pelo Termo de Convênio de Cooperação $n^{0}$ 022/2019, estabelecido entre a CEDAE e a UERJ para desenvolvimento e implementação do reuso no RJ (DOERJ de 12/11/19). Essa definição tomou ainda como base aspectos referentes à maior viabilidade tanto de fornecimento como pela demanda de uma mesma tipologia de águas regeneradas, considerando as capacidades de tratamento disponíveis nas ETE's e suas respectivas localizações.

Foram então definidas como potenciais fornecedores de água de reuso e "cases" prioritários as ETE’s Alegria, Penha, Pavuna e Sarapuí, as quatro maiores estações operadas pela CEDAE. Foram levantadas as suas principais características, incluindo localização, vazão e tecnologia de tratamento dos efluentes, além de informações sobre os sistemas de reuso disponíveis unicamente nas ETE’s Alegria e Penha. Operado pela Concessionária Zona Oeste mais Saneamento (ZOMS), o SPAR da ETE Deodoro não foi priorizado pelo presente estudo.

Desenvolvido com emprego dos softwares QGis e Google Earth, o mapa (Figura 1) apresenta a localização das ETE’s e as respectivas áreas de cobertura/atendimento de suas bacias/redes de esgotamento sanitário. Foi elaborado a partir das coordenadas geográficas dessas ETE's e respectivas áreas de cobertura das redes de esgoto contribuintes. Com a delimitação das áreas no Google Earth, foram gerados os arquivos que foram inseridos no QGis. Os dados utilizados se basearam em informações de Bielschowsky (2014) e CEDAE (2017; 2020). 


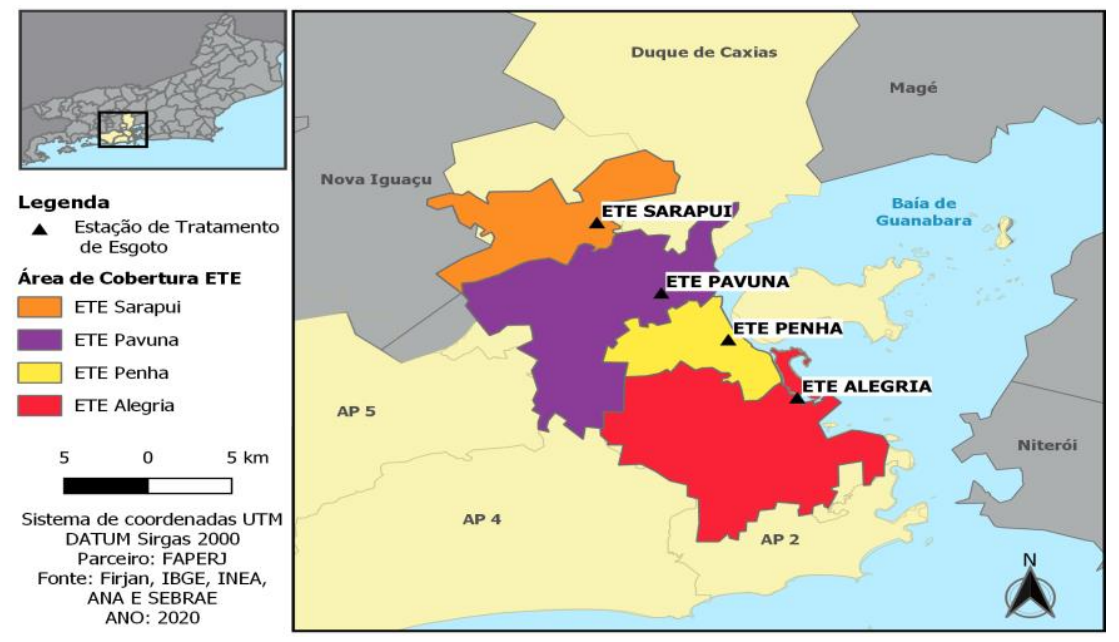

Figura 1. Mapa georreferenciado das ETEs elencadas como potenciais fornecedores e respectivas áreas de cobertura das redes de esgotamento sanitário.

Fonte: 0s autores (2020).

Durante essa etapa da pesquisa, foram observadas discrepâncias nas informações relacionadas às vazões de operação das 4 ETE’s estudadas, dependendo da fonte dos dados utilizada (BIELSCHOWSKY, 2014; OBRACZKA et al., 2019). No caso das ETE’s Alegria e Penha, por exemplo, dados obtidos referentes às suas vazões variavam de $1529 \mathrm{~L} / \mathrm{s}$ e $1200 \mathrm{~L} / \mathrm{s}$ (FARIA, 2020; FIRJAN, 2019) a 2.400 e $1.600 \mathrm{~L} / \mathrm{s}$ (FIRJAN, 2019; R0CHA, 2020), respectivamente. Foi então adotada como vazão de referência a capacidade instalada de tratamento secundário de cada ETE, bem como a capacidade instalada do sistema de produção de água de reuso, mesmo que esteja ele inoperante ou subutilizado. Essas informações serviram como premissas básicas para a avaliação quantitativa do potencial de oferta de água de reuso para fins não potáveis, que se configura como um dos objetivos do trabalho.

\section{ETAPA 2: Caracterização de potenciais consumidores de água de reuso na área de estudo}

Utilizando-se a ferramenta de livre acesso My Maps do Google (https://www.google.com/intl/pt-BR/maps/about/mymaps/) e com base nos dados do Cadastro Industrial da Federação das Indústrias do Estado do Rio de Janeiro (FIRJAN, 2016), em meio digital, fornecido pela própria FIRJAN, foi extraída a relação de 8004 empresas localizadas nos municípios do Rio de Janeiro, Belford Roxo, Duque de Caxias e São João de Meriti. Cabe destacar que o cadastro da FIRJAN abrange os mais diversos setores de atividades, inclusive comércios a varejo, distribuidoras, transportadoras, agências de viagens, escritórios de arquitetura e demais setores econômicos. Além disso, o cadastro contém informações relevantes e direcionadoras para o projeto, como: nome fantasia, endereço, bairro, cidade, estado, CEP, CNPJ, número de 
empregados, produto e setor de atividade. Após a extração, foi feita a tabulação das informações, elaborando-se uma planilha base para o desenvolvimento dos mapas.

0 processo de validação inicial das indústrias/empresas potenciais consumidoras de águas regeneradas foi realizado através da ferramenta My Maps do Google para o georreferenciamento, em conjunto com os dados do site da Receita Federal, para verificar a situação cadastral das empresas e proporcionar uma maior atualização quanto à validade dos dados. Em sequência, através do emprego do My Maps, foi possível extrair as coordenadas dos endereços cadastrados. A partir da consolidação dessas informações deu-se início às análises e adoção de filtros para inserção dos dados no QGiis.

Para determinação das tipologias industriais adotadas no estudo, foi utilizada a Classificação Nacional de Atividades Econômicas (CNAE), versão 2.0 (CNI, 2017). Segundo a CNI (2017), a CNAE é ordenada de forma hierarquizada em cinco níveis: seção, divisão, grupo, classe e subclasse. A estrutura completa contempla 21 seções, 87 divisões, 285 grupos, 673 classes e 1.301 subclasses. Na estimativa nacional de usos consuntivos da água, a indústria de transformação representa o terceiro maior uso, atrás do abastecimento humano e da agricultura irrigada (ANA, 2019). Foi, portanto, selecionada especificamente a seção C Indústrias de Transformação, composta por 24 divisões (códigos 10 a 33), e respectivas subdivisões hierárquicas em 103 grupos, 258 classes e 410 subclasses.

Suas divisões de 10 a 12 não foram consideradas, pois abrangem as indústrias alimentícias e de bebidas, que exigem parâmetros de qualidade de água bastante restritivos em seus respectivos processos (CNI, 2017). Assim sendo, o presente trabalho considerou as indústrias que se situam entre as divisões 13 a 33, excluindo a 18 - Impressão e reprodução de gravações. A título de exemplo, a Tabela 1 apresenta os códigos e denominação referentes à Divisão 13 (FABRICAÇ̃̃o DE PRODUTOS TÊXTEIS) da estrutura do CNAE 2.0. A Tabela 3 também fornece maiores detalhes quanto às nomenclaturas das divisões e respectivas tipologias do CNAE ora adotadas.

Na sequência do desenvolvimento/aprofundamento da pesquisa, a fim de se obter uma gama representativa e relevante de potenciais clientes, foram consideradas somente indústrias com 20 funcionários ou mais, ou seja, no mínimo de pequeno porte (EPP), de acordo com a classificação Serviço Brasileiro de Apoio às Micro e Pequenas Empresas - SEBRAE (SEBRAE, 2013), confrontando-se esse valor limite com os dados disponíveis sobre número de empregados das empresas no Cadastro da FIRJAN.

Além dessas indústrias de transformação das divisões 13 a 33 e com mais de 20 funcionários, no desenvolvimento do trabalho foram incluídas em caráter excepcional, 4 
centrais dosadoras de concreto (CDC's), localizadas no entorno da ETE Alegria, no bairro do Caju. Tal inclusão se baseou na viabilidade do emprego de águas regeneradas provenientes dessa ETE para atendimento da demanda prevista de água dessas empresas para elaboração de concreto, como apontado pela pesquisa de Silva Jr e Obraczka (2020).

Considerando os critérios e filtros adotados nessa Etapa (2), o levantamento de dados gerais das indústrias elencadas permitiu identificar e analisar inconsistências quanto a algumas informações encontradas, como fechamento/inatividade da empresa, erros nos endereços cadastrados, duplicidades e mesmo carência de informações mínimas. Esses casos específicos não foram então incluídos no rol de empresas avaliadas pela pesquisa.

As indústrias elencadas como potenciais consumidoras de águas regeneradas pelo estudo foram então identificadas nas proximidades das quatro principais ETEs da CEDAE na RMRJ que já dispõem ou planejam instalar sistemas de produção de reuso: Alegria, Penha, Pavuna e Sarapuí.

Restringiu-se, porém a inserção na base de dados às empresas consideradas como mais viáveis de serem atendidas com água de reuso, por se situarem em um raio (distância) máximo de $10 \mathrm{~km}$ a partir das ETE's elencadas. Esse pré-requisito atende a recomendação das pesquisas de Campos (2018) e Obraczka et al. (2019) como raio viável e mais restritivo para fornecimento de água de reuso por caminhão pipa para fins urbanos não potáveis, a partir de efluentes domésticos tratados da ETE Alegria.

Somente no caso específico do município de Duque de Caxias foram mapeadas as indústrias situadas além desse raio de $10 \mathrm{~km}$, tendo em vista a identificação de um grande potencial demanda/consumo de água industrial de plantas/empreendimentos localizados no Complexo da Refinaria de Duque de Caxias (REDUC).

\section{ETAPA 3: Levantamento de outorgas de captação e estimativa de consumo dos potenciais consumidores de água de reuso}

Em complemento à identificação e seleção das indústrias como clientes potenciais de águas de reuso para fins não potáveis, foram também apuradas informações específicas sobre seu potencial de demanda/consumo de água a partir de dados sobre outorgas de água. Para isso, foram levantados e utilizados os dados de outorgas de captação de água disponíveis em sistemas e bancos de dados do Instituto Estadual do Ambiente (INEA), órgão gestor de recursos hídricos no Estado do Rio de Janeiro.

A partir do levantamento da lista/relação de outorgas na Região Hidrográfica V - Baía de Guanabara foram identificadas as indústrias localizadas no entorno das ETE’s adotadas, 
limitando-se a área de abrangência com base no mesmo raio de viabilidade de $10 \mathrm{~km}$ adotado na etapa anterior. De maneira análoga, foram também contempladas as outorgas localizadas no município de Duque de Caxias, com intuito de incluir as indústrias da REDUC.

Pode ser observado que uma considerável parcela de indústrias na área de estudo não possui captação/outorga própria de água, sendo, portanto, atendidas por outras fontes de abastecimento como caminhões pipa, aproveitamento de águas pluviais, reuso e/ou mesmo pela rede da concessionária de abastecimento de água. Para estas indústrias, realizou-se uma estimativa de demanda de água retirada. Os coeficientes de cálculo de retirada e de consumo foram multiplicados pelo número de empregados obtendo-se uma estimativa de volume de água retirado e consumido por dia na indústria, com base na metodologia utilizada e apresentado pela ANA no documento “Água na Indústria: uso e coeficientes técnicos” (ANA, 2017).

A título de exemplo, a Tabela 1 apresenta os coeficientes de retirada e consumo estimados de água para a Divisão 13 (Fabricação De Produtos Têxteis) da estrutura CNAE 2.0, com respectivos grupos e classes, discriminando-se a porcentagem do consumo em relação à retirada total de água.

Tabela 1. Coeficientes de retirada e consumo e consumo percentual de água para a Divisão 13 (Fabricação De Produtos Têxteis) da estrutura do CNAE 2.0

\begin{tabular}{|c|c|c|c|c|}
\hline $\begin{array}{l}\text { Divisão/Grupo/Classe/Subclasse } \\
\text { Códigos }\end{array}$ & Denominação & $\begin{array}{l}\text { Coeficiente } \\
\text { retirada } \\
\text { (L/emp.dia) }\end{array}$ & $\begin{array}{l}\text { Coeficiente } \\
\text { Consumo } \\
\text { (L/emp.dia) }\end{array}$ & $\begin{array}{l}\text { Consumo } \\
\text { (\%) }\end{array}$ \\
\hline 13 & Fabricação de produtos têxteis & & & \\
\hline 13.1 & Preparação e fiação de fibras têxteis & & & \\
\hline $1311-1 / 00$ & Preparação e fiação de fibras de algodão & 1.347 & 263 & $19,5 \%$ \\
\hline $1312-0 / 00$ & $\begin{array}{l}\text { Preparação e fiação de fibras têxteis naturais, } \\
\text { exceto algodão }\end{array}$ & 2.908 & 567 & $19,5 \%$ \\
\hline $1313-8 / 00$ & Fiação de fibras artificiais e sintéticas & 6.473 & 1.262 & $19,5 \%$ \\
\hline $1314-6 / 00$ & Fabricação de linhas para costurar e bordar & 1.803 & 351 & $19,5 \%$ \\
\hline 13.2 & Tecelagem, exceto malha & & & \\
\hline $1321-9 / 00$ & Tecelagem de fios de algodão & 1.395 & 233 & $16,7 \%$ \\
\hline $1322-7 / 00$ & $\begin{array}{l}\text { Tecelagem de fios de fibras têxteis naturais, } \\
\text { exceto algodão }\end{array}$ & 1.319 & 220 & $16,7 \%$ \\
\hline $1323-5 / 00$ & $\begin{array}{l}\text { Tecelagem de fios de fibras artificiais e } \\
\text { sintéticas }\end{array}$ & 761 & 127 & $16,7 \%$ \\
\hline $1330-8 / 00$ & Fabricação de tecidos de malha & 2.292 & 382 & $16,7 \%$ \\
\hline $13.40-5$ & $\begin{array}{l}\text { Acabamentos em fios, tecidos e artefatos } \\
\text { têxteis }\end{array}$ & 4.204 & 791 & $18,8 \%$ \\
\hline 13.5 & $\begin{array}{c}\text { Fabricação de artefatos têxteis, exceto } \\
\text { vestuário }\end{array}$ & 594 & 504 & $84,8 \%$ \\
\hline
\end{tabular}

Fonte: Adaptado de ANA (2017).

Para as classes de indústria cujo coeficiente não foi explicitado pela ANA (2017), adotouse o menor valor do respectivo grupo ou, em último caso, aquele referente a divisão em que se enquadra a empresa analisada. A adoção dessa premissa mais conservadora é justificada pelo 
objetivo do trabalho de analisar a relação entre a oferta de água de reuso e a demanda por seus potenciais consumidores. Para as centrais dosadoras de concreto (CDC's), foram adotados os valores levantados por Zahner Filho (2014), a partir de dados de consumo de água aferidos para essas concreteiras no primeiro trimestre de 2013, considerando-se que tais dados se referem à água para uso industrial não potável.

\section{ETAPA 4: Geração de mapa georreferenciado de potenciais fornecedores e consumidores de água} de reuso

A partir das principais informações levantadas como limites geopolíticos (abairramento, município e estados), em conjuntos com os dados adquiridos/elaborados ao longo do projeto como coordenadas geográficas, tipologia, vazões de efluentes fornecidas pelas ETEs e de demanda de água das indústrias elencadas pelo estudo, foi desenvolvida uma base de dados georreferenciada.

Essa base de dados permitiu a geração de mapas apresentando os potenciais fornecedores e consumidores de água de reuso para fins não potáveis, utilizando o software QGIS 3.14.16 'Pi' como principal ferramenta, com auxílio de recursos como a extensão para os mapas bases e os raios de viabilidade do projeto. Os mapas foram sendo aperfeiçoados no decorrer da pesquisa, sendo adaptados às demandas que foram surgindo, ao mesmo tempo em que funcionaram como subsídio para o desenvolvimento das etapas subsequentes. Para cada tipologia industrial (divisão) foi adotado um símbolo (legenda) específico, com uma diferenciação por faixas da vazão diária requerida pelos potenciais consumidores da seguinte forma: a) de 2 a $100 \mathrm{~m}^{3} /$ dia; b) entre 100 e $1.000 \mathrm{~m}^{3} /$ dia e c) acima de $1.000 \mathrm{~m}^{3} /$ dia.

\section{ETAPA 5: Avaliação quantitativa das vazões ofertadas de efluente tratado e de água de reuso a partir das ETE's e das vazões demandadas pelos potenciais consumidores}

Com base no levantamento das capacidades instaladas de tratamento e de produção de água de reuso das quatro ETE’s, foi realizada uma avaliação de atendimento das demandas requeridas de água, considerando a tipologia (divisão) das indústrias elencadas como potenciais consumidores de água de reuso de duas formas. A primeira, mais genérica, contempla toda a região de estudo, enquanto a segunda foi feita de forma mais específica e detalhada, ou seja, considerando cada uma das quatro ETE's e sua respectiva área delimitada no raio de $10 \mathrm{~km}$ no seu entorno. 


\section{RESULTADOS E DISCUSSÃ0}

\section{Caracterização de potenciais fornecedores de água de reuso}

A Tabela 2 relaciona as quatro ETE’s elencadas para o presente estudo (Alegria, Penha, Pavuna e Sarapuí), apresentando informações e características básicas como sua localização, coordenadas geográficas, além de dados relacionados aos sistemas de tratamento secundário dos efluentes e aos sistemas de produção de água de reuso existentes.

Tabela 2. Principais características das ETE’s da Alegria, Penha, Pavuna e Sarapuí, adotadas como potenciais fornecedores de água de reuso na RMRJ.

\begin{tabular}{|c|c|c|c|c|c|}
\hline $\begin{array}{l}\text { Fonte } \\
\text { geradora } \\
(E T E)\end{array}$ & $\begin{array}{l}\text { Localização } \\
\text { (Bairro, Cidade) }\end{array}$ & $\begin{array}{l}\text { Tecnologia } \\
\text { tratamento }\end{array}$ & $\begin{array}{l}\text { Capacidade de } \\
\text { tratamento } \\
\left(\mathrm{m}^{3} / \mathrm{dia}\right)\end{array}$ & $\begin{array}{ll}\text { Capacidade } & \\
\text { instalada do } \\
\text { SPAR } & \\
\left(\mathrm{m}^{3} / \text { dia }\right) & \\
\end{array}$ & $\begin{array}{l}\text { Capacidade de reuso em } \\
\text { relação a de tratamento } \\
\text { (\%) }\end{array}$ \\
\hline Alegria & Сaju, RJ & Lodos ativados por & 216.000 & 1.920 & 0,89 \\
\hline Penha & Penha, RJ & $\begin{array}{l}\text { aeração } \\
\text { prolongada }\end{array}$ & 93.830 & 768 & 0,82 \\
\hline Sarapuí & Belford Roxo, RJ & Primário & 129.600 & - & - \\
\hline $\begin{array}{l}\text { Pavuna } \\
\text { Meriti }\end{array}$ & Pavuna, RJ & $\begin{array}{l}\text { quimicamente } \\
\text { assistido e lodos } \\
\text { ativados }\end{array}$ & 129.600 & - & - \\
\hline TOTAL & & & 353.030 & 2.688 & 0,76 \\
\hline
\end{tabular}

Fonte: Adaptado de Campos (2018); Obraczka et al. (2019) e Faria (2020).

Pode ser constatado que todas as ETE's avaliadas possuem tratamento a nível secundário, uma vez que, devido as suas elevadas cargas orgânicas afluentes (C>80 kg DB0/dia), esses sistemas demandam a faixa de remoção e de eficiência mais elevada da DZ 215- R4, a diretriz de controle de carga orgânica biodegradável em efluentes líquidos de origem sanitária no RJ, uma das mais restritivas do país (RI0 DE JANEIR0, 2007).

Observou-se que existe um enorme potencial para ampliação do sistema de produção de água de reuso, de uma maneira geral. Mesmo considerando a capacidade total instalada dos sistemas de produção de água de reuso (SPAR) nas ETEs Alegria $\left(1.920 \mathrm{~m}^{3} /\right.$ dia) e Penha (768 $\mathrm{m}^{3} / \mathrm{dia}$ ), a mesma não atinge a $1 \%$ da vazão total, considerando que essas ETE’s operem com toda sua capacidade de instalada de tratamento secundário, ou seja, de $353.030 \mathrm{~m}^{3} /$ dia.

Quando comparada a vazão (capacidade instalada) total de tratamento das quatro ETE’s, a vazão de reuso é ainda mais incipiente (cerca de 0,8\% desse total), caracterizando sua baixa participação na matriz hídrica e corroborando com o que sustentam autores como Campos (2018), Silva Junior et al. (2019) e Obraczka et al. (2019). Considerando as recorrentes situações de escassez e insegurança hídrica na RMRJ, esses autores afirmam se tratar de um grave desperdício o descarte simples de grandes vazões de efluente tratado de ótima qualidade para 
o corpo receptor. Esse aspecto é agravado em se tratando de um cenário de frequente dificuldade ou mesmo incapacidade das concessionárias em atender as demandas de água de grandes consumidores como as indústrias através do sistema convencional, seja pela carência de retaguarda, seja pelos preços cobrados pelo fornecimento de água potável.

Vale destacar que grande parte dos investimentos e custos operacionais necessários para viabilizar a produção de água de reuso já se encontra absorvido pelo próprio sistema de tratamento convencional existente nas ETEs elencadas. Como discriminado por autores como FARIA (2020) e 0BRACZKA et al. (2019), isso ocorre em função da alta qualidade do efluente tratado visando o atendimento das demandas e exigências da legislação ambiental do RJ - uma das mais restritivas do país - para o seu descarte nos corpos hídricos. Todas essas estações dispõem de sistemas/processos de lodos ativados ou, no mínimo, tratamento primário quimicamente assistido que garantem uma elevada eficiência de remoção de poluentes e consequentemente elevada qualidade do efluente tratado (VON SPERLING, 2005).

\section{Inventário de potenciais consumidores de água de reuso para fins não potáveis}

Sob o ponto de vista da demanda potencial por águas regeneradas, foram priorizadas as tipologias industriais situadas no rol de setores econômicos que mais consomem água no país, as denominadas indústrias de transformação, contemplando a divisão do CNAE 2.0.

Considerando os filtros pré-estabelecidos, como o raio máximo de $10 \mathrm{~km}$ e número mínimo de 20 empregados, a metodologia proposta identificou 728 indústrias situadas nas proximidades das fontes de água de reuso adotadas que se configuram como potenciais consumidores para as águas regeneradas provenientes dessas 4 ETEs (Alegria, Penha, Pavuna e Sarapuí). Apesar de classificadas com tipologia de indústrias de transformação, verificou-se que determinadas empresas cadastradas pela FIRJAN (2016) são na realidade escritórios representantes destas empresas, muitas deles situados na região central da cidade do Rio de Janeiro, cujas demandas são basicamente de água potável e para fins domésticos. Dessa forma, não foram incluídas nesse inventário.

A Tabela 3 apresenta uma compilação dos resultados obtidos quanto ao número de indústrias e respectiva vazão de demanda, por divisão/tipologia. 
Tabela 3. Quantidade e vazão requerida de água industrial por divisão/tipologia das indústrias de transformação, potenciais consumidoras de água de reuso das ETE’s Alegria, Penha, Pavuna e Sarapuí.

\begin{tabular}{|c|c|c|c|c|c|c|}
\hline & $\begin{array}{l}\text { Divisão } \\
\text { CNAE }\end{array}$ & Tipologia & $\begin{array}{l}\text { Núm. de } \\
\text { Indústrias }\end{array}$ & $\begin{array}{l}\text { Porcenta } \\
\text { gem }\end{array}$ & $\begin{array}{l}\text { Vazão de demanda } \\
\left(\mathrm{m}^{3} / \text { dia }\right)\end{array}$ & $\begin{array}{l}\text { Porcenta } \\
\text { gem }\end{array}$ \\
\hline 1 & 13 & Fabricação de produtos têxteis & 23 & $3 \%$ & $6.067,2$ & $4 \%$ \\
\hline 2 & 14 & $\begin{array}{l}\text { Confecção de artigos do vestuário e } \\
\text { acessórios }\end{array}$ & 111 & $15 \%$ & $8.987,7$ & $7 \%$ \\
\hline 3 & 15 & $\begin{array}{l}\text { Preparação de couros e fabricação de } \\
\text { artefatos de couro, artigos para } \\
\text { viagem e calçados }\end{array}$ & 9 & $1 \%$ & $1.451,6$ & $1 \%$ \\
\hline 4 & 16 & Fabricação de produtos de madeira & 2 & $*$ & 8,8 & * \\
\hline 5 & 17 & $\begin{array}{l}\text { Fabricação de celulose, papel e } \\
\text { produtos de papel }\end{array}$ & 32 & $4 \%$ & $1.108,6$ & $1 \%$ \\
\hline 6 & 19 & $\begin{array}{l}\text { Fabricação de coque, de produtos } \\
\text { derivados do petróleo errer de } \\
\text { biocombustíveis }\end{array}$ & 6 & $1 \%$ & $33.355,8$ & $25 \%$ \\
\hline 7 & 20 & Fabricação de produtos químicos & 79 & $11 \%$ & $51.743,6$ & $38 \%$ \\
\hline 8 & 21 & $\begin{array}{l}\text { Fabricação de produtos } \\
\text { farmoquímicos e farmacêuticos }\end{array}$ & 27 & $4 \%$ & $1.838,6$ & $1 \%$ \\
\hline 9 & 22 & $\begin{array}{l}\text { Fabricação de produtos de borracha e } \\
\text { de material plástico }\end{array}$ & 80 & $11 \%$ & $1.137,5$ & $1 \%$ \\
\hline 10 & 23 & $\begin{array}{l}\text { Fabricação de produtos de material } \\
\text { plástico }\end{array}$ & 24 & $3 \%$ & $3.023,8$ & $2 \%$ \\
\hline 11 & 24 & $\begin{array}{l}\text { Fabricação de produtos de minerais } \\
\text { não-metálicos }\end{array}$ & 16 & $2 \%$ & $4.269,7$ & $3 \%$ \\
\hline 12 & 25 & $\begin{array}{l}\text { Fabricação de produtos de metal, } \\
\text { exceto máquinas e equipamentos }\end{array}$ & 94 & $13 \%$ & $1.640,6$ & $1 \%$ \\
\hline 13 & 26 & $\begin{array}{l}\text { Fabricação de equipamentos de } \\
\text { informática, produtos eletrônicos e } \\
\text { ópticos }\end{array}$ & 13 & $2 \%$ & 154,0 & $*$ \\
\hline 14 & 27 & $\begin{array}{l}\text { Fabricação de máquinas, aparelhos e } \\
\text { materiais elétricos }\end{array}$ & 13 & $2 \%$ & 227,1 & $*$ \\
\hline 15 & 28 & $\begin{array}{l}\text { Fabricação de máquinas } \\
\text { equipamentos }\end{array}$ & 64 & $9 \%$ & $1.679,2$ & $1 \%$ \\
\hline 16 & 29 & $\begin{array}{l}\text { Fabricação de veículos automotores, } \\
\text { reboques e carrocerias }\end{array}$ & 11 & $2 \%$ & 74,1 & * \\
\hline 17 & 30 & $\begin{array}{l}\text { Fabricação de outros equipamentos } \\
\text { de transporte, exceto veículos } \\
\text { automotores }\end{array}$ & 7 & $1 \%$ & $13.498,5$ & $10 \%$ \\
\hline 18 & 31 & Fabricação de móveis & 25 & $3 \%$ & 107,6 & $*$ \\
\hline 19 & 32 & Fabricação de produtos diversos & 42 & $6 \%$ & $3.303,2$ & $2 \%$ \\
\hline 20 & 33 & $\begin{array}{l}\text { Manutenção, reparação e instalação } \\
\text { de máquinas e equipamentos }\end{array}$ & 46 & $6 \%$ & $1.819,4$ & $1 \%$ \\
\hline 21 & 42 & $\begin{array}{l}\text { Outras obras de engenharia civil não } \\
\text { especificadas anteriormente }\end{array}$ & 3 & * & 223,2 & $*$ \\
\hline \multirow[t]{2}{*}{22} & 43 & $\begin{array}{l}\text { Outras obras de acabamento da } \\
\text { construção }\end{array}$ & 1 & $*$ & 57,3 & $*$ \\
\hline & & TOTAL & 728 & & $135.777,0$ & \\
\hline
\end{tabular}

* valores inferiores a 0,5\% não foram considerados

Fonte: Os autores (2020).

Analisando-se os resultados do ponto de vista quantitativo, destacam-se indústrias das Divisões: (14) - Confecção; (20) - Produtos Químicos (especialmente, produtos petroquímicos/polímeros); (22) - Borracha/Plástico (artefatos de borracha e embalagens de material plástico) e (25) - Produtos de metal (estruturas metálicas, usinagem). Somadas elas perfazem 364 empresas, ou seja, 50\% das 728 elencadas pelo estudo. 
Já sob a ótica das vazões demandadas, destacam-se as Divisões: (19) - Coque e derivados de petróleo e (20) - Produtos Químicos (especialmente, produtos petroquímicos/polímeros), respectivamente com 25\% e 35\% da demanda. Considerando a vazão total estimada de 135.777 $\mathrm{m}^{3}$ /dia, o somatório somente dessas duas Divisões atinge a uma vazão de 85.099,4 m²/dia, o que representa cerca $63 \%$ da demanda total requerida no âmbito do cenário estudado. A Divisão (20) - Produtos Químicos (especialmente, produtos petroquímicos/polímeros) é a única que se destaca tanto em termos de quantidade de indústrias como de vazão requerida.

\section{Mapa georreferenciado de potenciais fornecedores e consumidores de água de reuso para fins não potáveis na área em estudo}

A compilação das principais informações serviu de base para o desenvolvimento de um inventário/mapa georreferenciado contemplando os potenciais fornecedores e consumidores de água de reuso na área em estudo.

A Figura 2 apresenta a localização georreferenciada dos quatro principais fornecedores (ETE's Alegria, Penha, Pavuna e Sarapuí) e dos potenciais consumidores de água de reuso não industrial (indústrias), por faixas de vazão diária demandada.

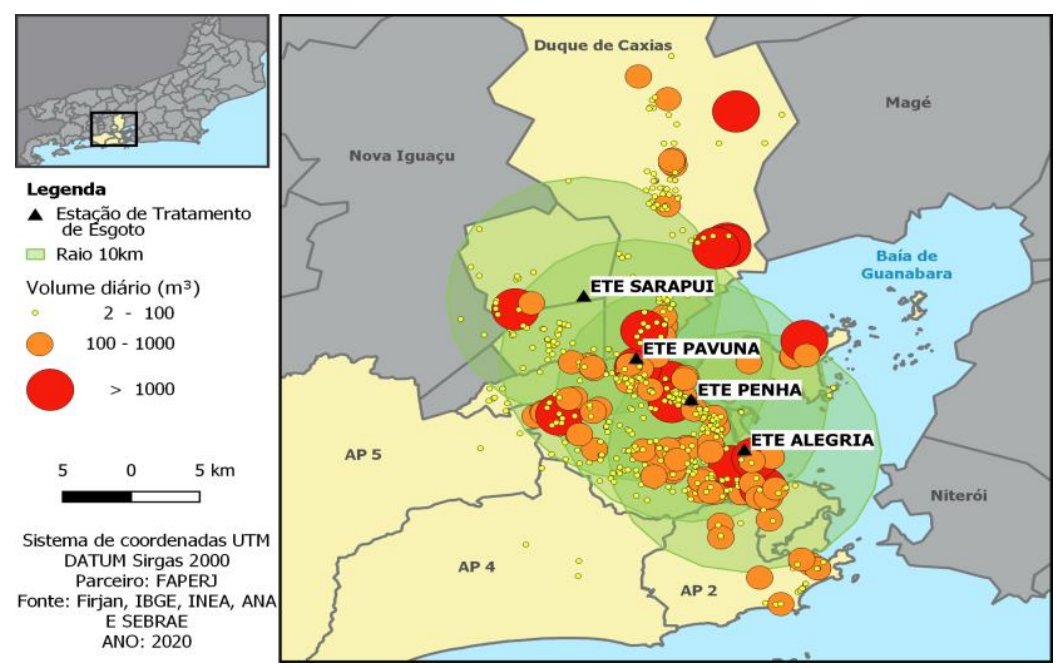

Figura 2. Mapa georreferenciado dos fornecedores de água de reuso (ETE’s) e dos consumidores(indústrias) por faixas de vazão diária demandada. Fonte: Os autores (2020).

A Figura 3 apresenta a localização georreferenciada dos potenciais fornecedores e consumidores, por tipologia industrial, destacando-se a região da ETE Alegria, no Caju. 


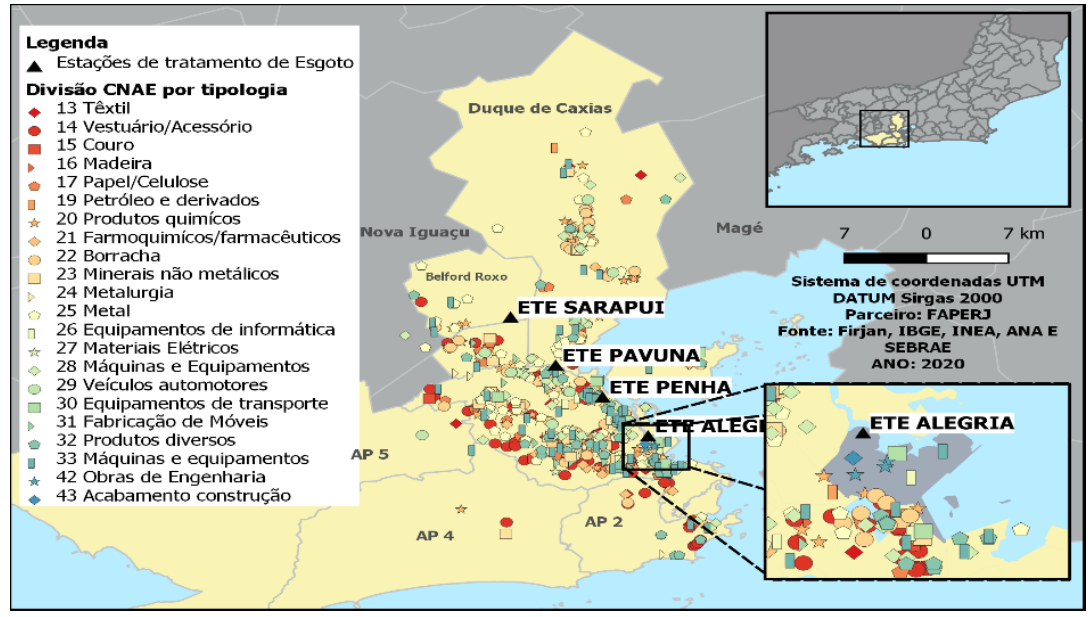

Figura 3. Mapa georreferenciado dos consumidores (indústrias) e fornecedores em potencial de água de reuso, por tipologia industrial.

Fonte: 0 s autores, 2020.

De uma maneira geral, pode ser visualizada a proximidade de dezenas (e mesmo de centenas) de empresas cadastradas pelo estudo em relação às ETE’s priorizadas. Considerando, por exemplo, o raio de viabilidade de $10 \mathrm{~km}$ pré-estabelecido como limite, constata-se ainda que muitas empresas podem ter suas demandas atendidas até mesmo por mais do que uma única ETE: 395 pela ETE Alegria, 517 pela ETE Penha, 430 pela ETE Pavuna e 227 pela ETE Sarapuí.

Localizadas mais próximas ao centro de massa das maiores demandas por água de reuso, as ETE Penha e Pavuna apresentam também um grande potencial para atendimento das demandas de várias empresas de pequeno, médio e grande porte situadas nas suas proximidades. Também a ETE Alegria se apresenta com bom potencial pela existência de uma grande concentração de indústrias de médio porte situadas no seu raio de abrangência. Apesar de mais distante no contexto geral das ETE’s avaliadas, a ETE Sarapuí é a que se localiza mais próxima do Complexo da REDUC, em Duque de Caxias (cerca de $12 \mathrm{~km}$ ). Mesmo que essa proximidade não se caracterize no raio limite de $10 \mathrm{~km}$ adotado, cabe destacar que as empresas da REDUC possuem um grande potencial para serem supridas por águas de reuso tendo em vista as grandes vazões de água industrial por elas demandadas, estimadas por este estudo em 65.415 $\mathrm{m}^{3} /$ dia.

Segundo a FIRJAN (2019), as ETE’s Sarapuí e Pavuna são as que concentram as principais oportunidades para aproveitamento de águas de reuso, em função das demandas hídricas do Polo Industrial de Campos Elíseos e da REDUC e as do Parque Industrial da Bayer (Belford Roxo).

Cabe ressaltar que em relação as 4 ETE’s, todas as indústrias elencadas no presente estudo se situam em raios inferiores ao máximo de $50 \mathrm{~km}$, avaliado como viável para 
atendimento por carro pipa pelos trabalhos de Campos (2018) e Obraczka et al. (2019). Segundo essas fontes, tais distâncias dependem de aspectos como: a) as vazões de demanda; b) as tarifas de água do sistema convencional e de água transportada por caminhão pipa e c) a qualidade da água disponível nos casos de emprego de suas fontes próprias, tais como águas subterrâneas.

Esse aspecto da qualidade da água necessária para cada tipologia de indústria ou processo industrial não foi abordado pelo presente trabalho. Porém, autores como Zahner Filho (2014),0dppes et al. (2018), Farias (2020) e Silva Jr e Obraczka (2020) destacam que a elevada qualidade apresentada em efluentes tratados de ETE's como a Alegria demonstra a grande potencialidade para o seu aproveitamento, se prestando, por exemplo, ao atendimento de demandas de água de amassamento(elaboração de concreto).

\section{Avaliação do potencial de vazão de água de reuso ofertado em comparação com a demanda potencial de água industrial.}

0 Gráfico 1 apresenta as capacidades instaladas de tratamento secundário das ETE's Alegria, Penha, Pavuna e Sarapuí bem como dos sistemas de produção de reuso (SPAR) das ETE’s Alegria e Penha, comparadas ao somatório das vazões estimadas de demanda de água industrial das 728 indústrias elencadas pela pesquisa.

Gráfico 1. Capacidade de produção de efluente tratado (ET) das ETE’s Alegria, Penha, Pavuna e Sarapuí e de água de reuso (AR) das ETE’s Alegria e Penha e demanda de água das indústrias.

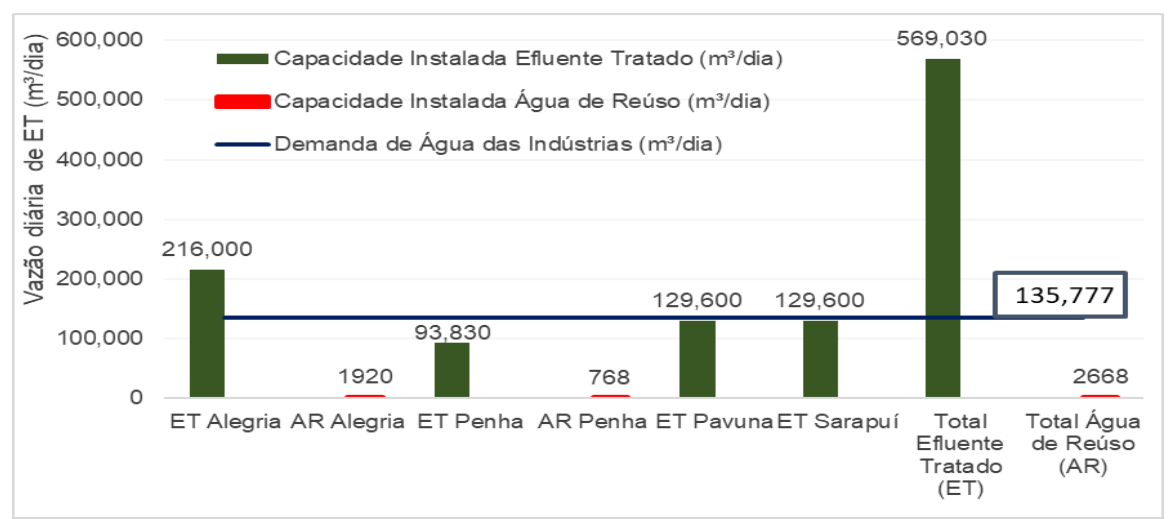

Fonte: 0s autores (2020).

Observou-se que somente a capacidade instalada dos sistemas de água de reuso existentes (SPAR das ETE’s Penha e Alegria) não é suficiente para atender à demanda total dos potenciais consumidores cadastrados. Por outro lado, se for considerada a capacidade instalada de tratamento de esgotos a nível secundário, a da ETE Alegria já seria suficiente para suprir 
toda a demanda estimada por água de reuso requerida pelas 728 indústrias elencadas pelo estudo. Tanto a ETE Pavuna como a ETE Sarapuí poderiam atender, individualmente, a 95\% da demanda de vazão de águas regeneradas estimada para essas indústrias. 0 somatório da capacidade instalada de tratamento das ETE’s Alegria, Penha, Pavuna e Sarapuí seria suficiente para atender a cerca de 4 vezes a demanda estimada total para fins industriais/não potáveis dos potenciais consumidores de água de reuso ora elencados. Mesmo que seja considerada apenas a vazão total de operação dessas 4 ETE’s (de cerca de 3 m³ s ou $259.200 \mathrm{~m}^{3} /$ dia), mencionada por fontes como OBRACZKA et al. (2019) e Faria (2020), seria possível, portanto, atender a cerca de 2 vezes demanda industrial estimada pela pesquisa.

Implementar o aproveitamento de água de reuso a partir da vazão total $\left(569.030 \mathrm{~m}^{3} / \mathrm{dia}\right)$ ou operacional (259.200 m³/dia) somente dessas 4 ETE’s pode contribuir na geração de uma maior oferta de água potável na RMRJ. A título de exemplo, o emprego dessas vazões de água de reuso representa um potencial de redução de 18 ou 8\%, respectivamente, na vazão total de abastecimento de água do sistema Guandu, se for considerada a capacidade de cerca de 4268160 $\mathrm{m}^{3} /$ dia $\mathrm{m}^{3} / \mathrm{s}$, discriminada pelo INEA (http://www.inea.rj.gov.br/ar-agua-e-solo/segurancahidrica/sistemas-de-abastecimento/guandu-lajes-acari/), considerando-se uma perda de cerca 26\% no respectivo sistema de adução/distribuição (ITB/G0, 2018).

Sob essa ótica, tanto Cunha (2008) como Silva Jr. e Obraczka (2020) sustentam que a prática do reuso de efluentes se configura tanto como uma fonte alternativa de água como um instrumento estratégico para melhoria da gestão de recursos hídricos, aumentando a segurança hídrica e ainda reduzindo a poluição no meio ambiente.

Especialmente em se tratando de áreas urbanas brasileiras, a vocação para o reuso é para fins industriais não potáveis, considerando o proibitivo custo da água potável para as demandas do mundo corporativo (HESPANHOL e GONCSALVES, 2004; FIRJAN, 2019 e FARIA, 2020). 0 reuso direto de efluentes tratados para fins não nobres, como a sua utilização para fins industriais, ou na construção civil, revela-se como um fator positivo na gestão de recursos hídricos, poupando a utilização dos mananciais para o abastecimento e produção de alimentos (HESPANHOL, 2008).

Para essa finalidade, são necessárias ações/medidas que incentivem o reuso, entre elas: o estabelecimento de processo ágil de gestão de recursos hídricos/outorga/licenciamento; redução da atual insegurança jurídica e institucional para os potenciais fornecedores e consumidores; e reavaliação dos atuais (e insignificantes) valores de outorga de uso de água de mananciais convencionais. 


\section{CONCLUSÃO}

0 presente artigo apresentou um inventário georreferenciado de potenciais fornecedores e consumidores de água de reuso na área estudada, que abrange boa parte da RMRJ. A metodologia proposta permitiu ainda identificar potencialidades e oportunidades de reuso dos efluentes tratados para fins industriais não potáveis nas 4 ETE’s priorizadas pelo estudo: Alegria, Penha, Pavuna e Sarapuí.

Em função da grande capacidade instalada de seus sistemas de tratamento secundário e da boa qualidade característica desses efluentes, foi possível inferir a existência de um grande potencial de produção de água de reuso como fonte alternativa de abastecimento de água para fins industriais na RMRJ. Trata-se de nichos de mercado que não são atualmente atendidos pelo sistema convencional - em função do alto/proibitivo custo dessa água potável - mas que podem ser supridos por águas de reuso, gerando novas oportunidades de receita para as concessionárias. As quatro ETE’s possuem capacidade instalada/vazão de tratamento para atender cerca de quatro vezes a demanda total de água industrial estimada para as 728 indústrias de transformação que se configuram, de acordo com o estudo, como potenciais consumidores de águas regeneradas. Essas empresas estão situadas nos raios de $10 \mathrm{~km}$ a partir de cada sistema de tratamento (ETE), limite esse que foi adotado pelo presente trabalho como distância máxima viável para seu atendimento com águas de reuso.

Dentre os potenciais consumidores, destaca-se a elevada demanda de água das seguintes tipologias (Divisão) de indústrias: a) Confeç̧ões (14); b) Fabricantes de borracha e plástico (22); c) Fabricantes de produtos de metal (25); d) Fabricantes de coque, derivados de petróleo e biocombustíveis (19); e e) Fabricantes de Produtos Químicos (especialmente, produtos petroquímicos/polímeros) (20). Somente esses dois últimos, somados, representam $64 \%$ da demanda requerida na área de estudo.

0 inventário e os dados gerados pela pesquisa podem ser utilizados como suporte para planejamento e gestão de recursos hídricos e saneamento e como uma ferramenta de apoio à decisão e a implementação da prática de reuso de efluentes na RMRJ, considerando que os efluentes tratados disponíveis podem atender também a demandas de água de outras tipologias industriais. Porém, para uma análise mais criteriosa desse potencial e de sua viabilidade de atendimento se faz necessária uma melhor caracterização desses efluentes, a luz da qualidade mínima necessária para suprir tais demandas. 
Cabe ainda mencionar as limitações do estudo em função das discrepâncias relativas às fontes de dados utilizadas, como no caso das capacidades instaladas e vazões operacionais de tratamento das ETE's avaliadas corroborando, portanto, com a necessidade de um maior aprofundamento da pesquisa, abrangendo dados mais robustos tanto no aspecto quantitativo como no qualitativo.

\section{AGRADECIMENTOS}

Os autores agradecem a CEDAE pela cessão de relevantes dados para o desenvolvimento do trabalho bem como a FAPERJ pelo fomento a pesquisa através do projeto REGEN - Águas Regeneradas para reuso na região metropolitana do Rio de Janeiro como alternativa à crise hídrica, referente ao Edital FAPERJ E_12/2018 - Apoio às Universidades Estaduais do RJ.

Agradecimentos aos autores:

Marcelo Obraczka - pela contribuição técnica com diversos trabalhos relacionados ao tema. Pela revisão na edição do trabalho. Luís Carlos Soares da Silva Junior pela contribuição técnica com diversos trabalhos relacionados ao tema. Pela revisão na edição do trabalho.

Kelly Oliveira pela elaboração de planilhas e na compilação dos mapas georreferenciados por meio das ferramentas My Maps, software QGIS (Sistema de Informação Georreferenciada).

Bruno Muricy pela elaboração de planilhas e no levantamento e compilação de informações apuradas nos cadastros de indústrias do Estado do Rio de Janeiro.

Ana Cecília Monteiro pela apuração dos dados relacionados às demandas de água por meio de levantamento no banco de dados de outorgas de captações de água e pesquisas relacionadas às estimativas de consumo de água nas indústrias.

\section{REFERÊNCIAS BIBLIOGRÁFICAS}

AGÊNCIA NACIONAL DE ÁGUAS - ANA (Brasil). Água na Indústria: Uso e Coeficientes Técnicos. -- Brasília: ANA, 2017. AGÊNCIA NACIONAL DE ÁGUAS - ANA (Brasil). Conjuntura dos Recursos Hídricos no Brasil. Brasília: ANA, 2019.

ANGELAKIS, A. N.; GIKAS, P. Water reuse: 0verview of current practices and trends in the world with emphasis on EU states. Water Utility Journal 8: 67-78, 2014.

BIELSCHOWSKY, M. C. Modelo de gerenciamento de lodo de Estação de Tratamento de Esgotos: aplicação do caso da Bacia da Baía de Guanabara. 2014. Dissertação - Escola Politécnica e Escola de Química, Programa de Engenharia Ambiental, UFRJ. 
CAMPOS, A. M. S. Aproveitamento de efluente tratado proveniente da ETE Alegria para reuso em áreas urbanas. Rio de Janeiro, 2018. Projeto final de graduação em Engenharia Civil - Faculdade de Engenharia - Universidade do Estado do Rio de Janeiro, 2018.

COMPANHIA ESTADUAL DE ÁGUAS E ESG0TOS - Origem da Companhia - Disponível em $\langle$ https://www.cedae.com.br/origem $>$. Acesso em 23 de setembro de 2020.

COMPANHIA ESTADUAL DE ÁGUAS E ESGOTOS - CEDAE. Relatório de Sustentabilidade 2017. Relatório. Rio de Janeiro, 2017.

CONFEDERAÇÃO NACIONAL DA INDÚSTRIA (CNI).Reuso de Efluentes: Metodologia para análise do potencial do uso de efluentes tratados para abastecimento industrial. 2017

CUNHA, V. D. 0 Reuso da Água e suas Possibilidades na RMSP. 2008. Dissertação (mestrado) - Universidade de São Paulo, Escola, São Paulo.

DIARIO OFICIAL DO ESTADO DO RIO DE JANEIR0 - DOERJ. ANO XLV. n 215 - Parte I, de 12 de novembro de 2019, pg 27. Extrato de Termo de Convênio de Cooperação no 022/2019. PROCESSO: Nº E-26/007/9173/2019.

EMPINOTTI,V.L.;BUDDS,J.;AVERSA,M.Governance,and water security:The role of the water institutional framework in 2013-15 water crisis in São Paulo,Brazil.V.98.Jan, 2019.

FARIA, A. A. DE. Análise do potencial de reuso de água para fins não potáveis a partir do efluente tratado de Estações de Tratamento de Esgotos na Região Metropolitana do Rio de Janeiro. [s.l.] Universidade do Estado do Rio de Janeiro, 2020.

FEDERAÇÃO DAS INDÚSTRIAS DO ESTADO DO RIO DE JANEIRO - FIRJAN. Cadastro Industrial do Estado do Rio de Janeiro 2015/2016. Rio de Janeiro, 2016.

FEDERAÇÃO DAS INDÚSTRIAS DO ESTADO DO RIO DE JANEIRO - FIRJAN. Oportunidades e desafios para o reúso de água na indústria do Rio de Janeiro Rio de Janeiro. NOTA TÉCNICA - JUNH0/2019. Disponível em www.firjan.com.br/publicacoes.

FORMIGA-JOHNSSON, R. M.; BRITTO, A. L.; CARNEIR0, P. R. F. - Abastecimento público e escassez hidrossocial na Metrópole do Rio de Janeiro, 2015

HESPANHOL, I.; GONÇALVES, O.M. (Coord.). Conservação e Reúso de Água - Manual

de Orientações para o setor industrial - Volume 1. FIESP/CIESP (org.): São Paulo, 2004. https://edisciplinas.usp.br/pluginfile.php/4418756/mod_resource/content/1/Manual\%20de\%20Conserva\%C3\%A7\% C3\%A30\%20e\%20Re\%C3\%BAso\%20FIESP.pdf

HESPANHOL I. Um novo paradigma para a gestão de recursos hídricos. DOSSIÊ ÁGUA

Estudos Avançados Estud. av. vol.22 no.63 São Paulo 2008 Disponível em https://www.scielo.br/scielo.php?script=sci_arttext\&pid=S0103-40142008000200009

HOEKSTRA, A.Y., CHAPAGAIN, A.K., ALDAYA, M.M. e MEKONNEN, M.M. The water footprint assessment manual: Setting the global standard, Earthscan, London, UK. 2016.

INSTITUTO TRATA BRASIL/G0 ASSOCIADOS - Perdas de Água 2018 (SNIS 2016): Desafios para Disponibilidade Hídrica e Avanço da Eficiência do Saneamento Básico. $\quad$ Disponível em http://www.tratabrasil.org.br/images/estudos/itb/perdas-2018/estudo-completo.pdf

INSTITUTO TRATA BRASIL - Demanda Futura por Água Tratada nas Cidades Brasileiras - 2017 a 2040. Agosto 2020.

MACHADO, FLÁVIO. 30 Congresso Brasileiro de Engenharia Sanitária e Ambiental - CBESA - 16 a 19/06/2019. NatalRN - Apresentação: Reuso de Efluentes na composição da matriz hídrica da Região Metropolitana de São Paulo. 2019

MARENG0, J. A.; NOBRE, C.A.; SELUCHI, M.E.; CUARTAS, A.; ALVES, L.M.; MEDIONDO, E.M.; OBREGÓN, G.; SAMPAIO, G. A seca e a crise hídrica de 2014-2015 em São Paulo. Revista USP, n. 106, 2015, p.31-44. 
MIERZWA, J.C. Visão Geral do Reuso no Brasil. III Simpósio Internacional de Reuso de Água - ABES/PR. $1^{0}$ webinar. Curitiba, 16 de novembro de 2020. Disponível em https://www.youtube.com/watch?v=PmaK8jqUtI\&list=PLmmxvdljpDtEESmBX65mjWWtwBNloIi8UGindex=1

NETO, J. N. V.; OLIVEIRA, J. R. C. Desafios e perspectivas do reuso de esgotos sanitários em áreas urbanas: 0 projeto da ETE Penha - CEDAE. Rio de Janeiro: CEDAE, 26 mar 2008. 27 p. Relatório técnico.

NOBRE, P Reuso de Água e Efluentes: A visão das Concessionárias. Seminário Internacional sobre Reuso de Agua. São Paulo 19 de março de 2013

OBRACZKA, M.; SILVA, D. R.; CAMPOS, A. S., (2019), Reuso de efluentes de tratamento secundário como alternativa de fonte de abastecimento de água no município do Rio de Janeiro. Sistemas \& Gestão, Vol. 14, No. 3, pp. $291-309$.

ODPPES, R. J.; MICHALOVICZ, D. T.; BILOTTA, P. Reúso de água em indústria de fabricação de estruturas em concreto: uma estratégia de gestão ambiental. R. Tecnol.Soc., Curitiba, v. 14, n. 34, p. 82-100, out./dez. 2018.

ORGANIZAÇÃO DAS NAÇÕES UNIDAS, Relatório Mundial sobre o Desenvolvimento da Água das Nações Unidas. 2019.

RI0 DE JANEIR0 - DZ 215. R-4. Diretriz de Controle de Carga Orgânica Biodegradável em Efluentes Líquidos de Origem Não Industrial- INEA, de 25 de setembro de 2007.

R0CHA C.T. da, 2020. Análise do Potencial de Reúso de Águas Residuárias no Estado do Rio de Janeiro: Estudo de Caso da ETE São Gonçalo, ETE Penha e ETE Alegria. Trabalho de Conclusão de Curso (TCC) de Graduação em Enga Ambiental da Univ. Veiga de Almeida.

SEBRAE (Org.) Anuário do trabalho na micro e pequena empresa: 2013. 6. ed./Serviço Brasileiro de Apoio às Micro e Pequenas Empresas; Departamento Intersindical de Estatística e Estudos Socioeconômicos - Brasília, DF; DIEESE, 2013. 284 p. ISSN 1983-2095.

SILVA JUNIOR, L. C. S;ARAUJO, B.M.; SANTOS, A.S.P.; OBRACZKA, M.;BOTTREL,S.E.C. Panorama do reuso de efluentes nas estações de tratamento de esgotos nas concessionárias de saneamento da Região SE.In:30 Congresso ABES Natal,RN. 2019.

SILVA JUNIOR, L.C.S.; OBRACZKA, M. Reuso de Efluentes de Estações de Tratamento de Esgoto no Beneficiamento de Concreto. MIX Sustentável, v. 6, n. 4, p. 85-92, ago. 2020.

SISTEMA FIRJAN. Manual de conservação e reúso de água na indústria. Hespanhol I. (Coordenador), Mierzwa J. C., Rodrigues L. Di B.e Silva, M. C. C. da, 2015 Centro Internacional de Referência em Reúso de Água - CIRRA/IRCWR Rio de Janeiro: [s.n],.35 p.: il., color.

STEFLOVÁ, M.; KOOP, S.; ELELMAN, R.; VINYOLES, R.; VAN LEEUWEN, K. Governing Non-Potable Water-Reuse to Alleviate Water Stress: The Case of Sabadell, Spain. 2018.

VON SPERLING, M. Introdução a Qualidade das Aguas e ao Tratamento de Esgotos. 3a Edição, Belo Horizonte. DESA/UFMG, 2005.

ZAHNER FILHO, E. Água de reuso: estudo para fornecimento como água de amassamento. Niterói, 2014. Dissertação apresentada ao Programa de Pós-Graduação em Engenharia Civil da Universidade Federal Fluminense, 2014. 